\title{
Non-enzymatic glycation reduces heparin cofactor II anti-thrombin activity
}

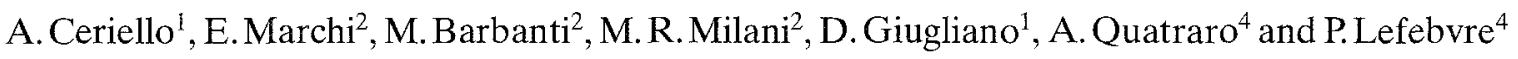 \\ ${ }^{1}$ Cattedra di Diabetologia e Dietoterapia I Facolta di Medicina, Universita di Napoli, Napoli, ${ }^{2}$ Alfa Ricerche, Bologna, \\ ${ }^{3}$ Centro di Diabetologia, Casa di Cura S. Rita, Taranto, Italy, ${ }^{4}$ Division of Diabetes, Nutrition and Metabolic Disorders, \\ University of Liège, Liège, Belgium
}

\begin{abstract}
Summary. The effects of non-enzymatic glycation on heparin cofactor II activity, at glucose concentrations which might be expected in physiological or diabetic conditions have been evaluated in this study. Radiolabelled glucose incorporation was associated with a loss of heparin cofactor anti-thrombin activity. The heparin cofactor heparin and dermatan sulfatedependent inhibition of thrombin was significantly reduced, showing a remarkable decrease of the maximum second order rate constant. This study shows that heparin cofactor
\end{abstract}

can be glycated at glucose concentrations found in the blood, and that this phenomenon produces a loss of heparin cofactor-antithrombin activity. These data suggest, furthermore, a possible link between heparin cofactor glycation and the pathogenesis of thrombosis in diabetes mellitus.

Key words: Heparin cofactor II, glycation, anti-thrombin activity, heparin, dermatan-sulfate.
Heparin-cofactor II (HCII) is a plasma protease inhibitor which inhibits thrombin by forming a stable 1:1 molar complex [1-5]. It is well known that the thrombin inhibitory activity of $\mathrm{HCII}$ is dramatically accelerated by some sulfated polysaccharides such as heparin and dermatan sulfate [6].

In vivo studies indicate both increased fibrinogen turnover and fibrinopeptide A levels in diabetic patients [7-8], and it has been suggested that an abnormal plasma or vascular environment is a more likely basis for this phenomenon. It is interesting that heparin infusion restores fibrinogen survival [7] and reduces the hyperglycaemiadependent increase of fibrinopeptide $A$ [8] in diabetic subjects. Correction by heparin suggests that such abnormality may be related to the action of thrombin or its inhibitors. This hypothesis is supported by the evidence that antithrombin III, a physiological thrombin-inhibitor, shows decreased activity in diabetes, due to non-enzymatic glycation [9-11].

Since HCII is another thrombin inhibitor, the possibility that non-enzymatic glycation may influence its activity, as well as antithrombin III, has been evaluated in this study.

In our studies, in vitro non-enzymatic glycation of HCII has been conducted at a physiological concentration of HCII $(1.2 \mu \mathrm{mol} / \mathrm{l})$ and glucose $(5 \mathrm{mmol} / \mathrm{l})$. In addition, a glucose concentration was used that closely approximates the condition that might be expected in severe diabetes
$(15 \mathrm{mmol} / \mathrm{l})$. We have carefully evaluated the inhibition kinetics of thrombin by glycated HCII and have compared the results with non-glycated HCII.

\section{Materials and methods}

HCII (chemical purity assured at greater than $99 \%$ by the manufactures), human serum albumin (HSA), and thrombin were supplied by Boehringer Mannheim (Mannheim, FRG). Porcine mucosa heparin (168 units/mg, $\left.\mathrm{M}_{\mathrm{r}} 7000-20000\right)$ and porcine skin dermatan sulfate $\left(\mathrm{M}_{\mathrm{r}} 20000-40000\right)$ were purchased from Sigma (St. Louis, Miss, USA).

$\mathrm{D}-\left(\mathrm{U}-{ }^{14} \mathrm{C}\right)$-glucose was purchased from Amersham (Arlington Heights, Ill., USA). This was initially purified to remove unwanted contaminants that are known to modify proteins faster than glucose itself [12]. To accomplish this, $150 \mu \mathrm{Ci} \mathrm{D}$-(U- $\left.{ }^{14} \mathrm{C}\right)$-glucose was incubated with $1.5 \mathrm{mg}$ bovine serum albumin in $1 \mathrm{ml} 0.2 \mathrm{~mol} / 1$ sodium posphate, $\mathrm{pH} 8$, for 2 days at $37^{\circ} \mathrm{C}$. Free glucose was separated from the protein-bound glucose by chromatography in Sephadex G-25. This fraction of free glucose was used for subsequent non-enzymatic glycation of HCII. Non-enzymatic glycation of HCII was carried out as follows. Six $3 \mathrm{ml}$ solutions of HCII $(1.2 \mu \mathrm{mol} / 1)$ were incubated at $37^{\circ} \mathrm{C}$ in $0.15 \mathrm{~mol} / / \mathrm{NaCl}, 0.02 \mathrm{~mol} / \mathrm{l}$ tris- $\mathrm{HCl}$, $\mathrm{pH} 7.4$. The first contained $5 \mathrm{mmol} / \mathrm{l}$ glucose, the second $5 \mathrm{mmol} / \mathrm{l}$ glucose plus $0.6 \mathrm{mmol} / \mathrm{l} \mathrm{HSA}$, the third $15 \mathrm{mmol} / /$ glucose, the fourth $15 \mathrm{mmol} / 1$ glucose plus $0.6 \mathrm{mmol} / \mathrm{HSA}$, the fifth was used as control and contained no glucose or HSA, the sixth contained only HSA at $0.6 \mathrm{mmol} / \mathrm{l}$. Sodium azide $(0.02 \%)$ was added to prevent bacterial growth, and the mixtures were incubated for 15 days. Fifty microcuries of $\mathrm{D}-\left(\mathrm{U}-{ }^{14} \mathrm{C}\right)$-glucose $(230 \mu \mathrm{Ci} / \mathrm{mol})$ was added as a tracer. 

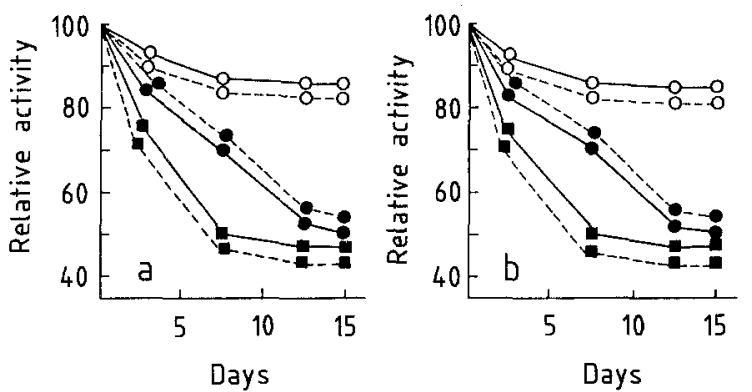

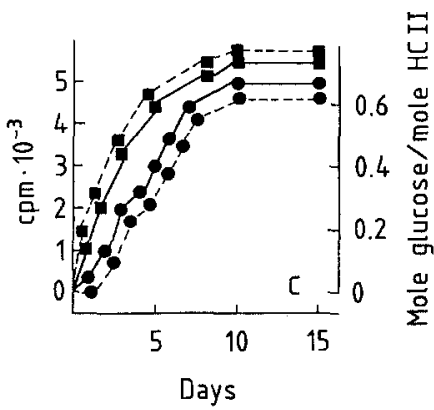

Fig.1a-c. Effects of nonenzymatic glycation on heparin cofactor II (HCII).

a HCII-heparin activity and

b HCII-dermatan-sulfate activity, as function of time. $\mathbf{c}$ Time-dependent incorporation of $\mathrm{D}$ - $\left(\mathrm{U}-{ }^{14} \mathrm{C}\right)$-glucose radioactivity in $\mathrm{HCII}$. Control HCII with (O---O) or without $(\mathrm{O}-\mathrm{O})$ albumin. HCII at glucose concentration of $5 \mathrm{mmol} / \mathrm{l}$ with $(\bullet-\cdots)$ ) or without $(\bullet)$ albumin. HCII at glucose concentration of $15 \mathrm{mmol} / \mathrm{l}$ glucose with (-- $)$ or without $(-\mathbf{m})$ albumin
Aliquots withdrawn at various times were passed through BioGel P. 10; HSA was separated by affinity chromatography on AffiGel Blue [13], followed by gel filtration on Bio-Gel P. 150 (Bio Rad Lab., Richmond, Calif., USA). The protein fractions were subsequently dialysed. Radioactivity was determined in two ways: (1) counts were made directly on dialysed protein solution; (2) the exhaustively dialysed solutions were treated with cold $10 \%$ trichloroacetic acid (TCA) and filtered through a nitrocellulose filter followed by extensive washing. Radiolabelled glucose bound to the protein was held in the nitrocellulose filter, while free radiolabelled glucose was eliminated with filtrate. Excess TCA in the filter was decomposed by drying the filter over a heat lamp for $5 \mathrm{~min}$, and the radioactivity in the filter was subsequently counted.

The dialysed proteins were assayed for HCII thrombin-inhibition activity in the presence of heparin or dermatan sulfate. Thrombin-inhibition reaction was carried out in triplicate in $1.5 \mathrm{ml}$ polyprolylene microcentrifuge tubes at $37^{\circ} \mathrm{C}$. Thrombin $(2.2 \mathrm{mmol} / \mathrm{l})$, HCII or glycated HCII $(1.2 \mu \mathrm{mol} / \mathrm{l})$ plus heparin $(0.5 \mathrm{U} / \mathrm{ml})$ or dermatan sulfate $(100 \mu \mathrm{g} / \mathrm{ml})$ were mixed in a buffer containing $0.15 \mathrm{~mol} / 1$ $\mathrm{NaCl}, 0.02 \mathrm{~mol} / 1$ Tris- $\mathrm{HCl}, \mathrm{pH} 7.4$ and $1 \mathrm{mg} / \mathrm{ml}$ bovine serum albumin [14]. After $20 \mathrm{~min}$, protease activity was determined by the addition of an equal volume of the appropriate chromogenic substrate $(\mathrm{S}-2238)$ in water. Hydrolysis of the substrate was terminated after $3 \mathrm{~min}$ by the addition of $1 / 10$ volume of $50 \%$ (volume/volume) acetic acid, the precipitated glycosaminoglycan was removed by centrifugation and the absorbance of the supernatant solution was determined at $405 \mathrm{~nm}$. In the absence of HCII, a standard curve of $\Delta 405$ thrombin dilutions was carried out, and the residual thrombin activity in the experiments expressed as a percentage of this reference curve.

The second-order rate constant $\left(\mathrm{K}_{\mathrm{m}}\right)$ of the HCII-thrombin interaction was determined using a synthetic substrate S-2238 [15].

\section{Results}

Figures $1 \mathrm{a}$ and $1 \mathrm{~b}$ show the effect of glycation on the HCII activity. Assays of aliquots withdrawn from the reaction mixtures (after chromatography and dialysis) revealed a time-dependent loss of activity. During incubation the control HCII $(0.15 \mathrm{~mol} / 1 \mathrm{NaCl}, 0.02 \mathrm{~mol} / \mathrm{l}$ Tris- $\mathrm{HCl}, \mathrm{pH} 7.4$, no glucose) lost some $\mathrm{HCII}$ activity up to a maximum of $15 \%$ after 7 days. The presence of HSA did not interfere with this phenomenon. The incubation mixture of HCII in $5 \mathrm{mmol} / \mathrm{l}$ glucose lost $30 \%$ and $\mathrm{HCII}$ in $15 \mathrm{mmol} / \mathrm{l}$ glucose lost $50 \%$ of the activity in 7 days. After 15 days the same amount of activity was lost whether the incubation was done at 5 or $15 \mathrm{mmol} / 1$ glucose. Incubation in the presence of HSA did not significantly influence these results. When HCII was incubated in 5 and $15 \mathrm{mmol} / \mathrm{l}$ glucose containing a tracer amount of $\mathrm{D}-(\mathrm{U}$ ${ }^{14} \mathrm{C}$ )-glucose, significant radioactivity was gradually incorporated into the protein (Fig. 1c). This was demonstrated by analysis of $\mathrm{HCII}$ bound radioactivity after gel filtration and extensive dialysis of aliquots obtained from the reaction mixture at various times. Similarly, TCA precipitation of the protein in aliquots obtained at various times revealed radioactivity associated with the precipitated protein. The incorporation of radioactivity at $15 \mathrm{mmol} / \mathrm{l}$ glucose was essentially linear for at least 4 days, but it is not clear why apparent levelling off of radioactivity occurred after 4 days. This may be associated with the glucose-dependent cross-linking of the protein [16] known to occur during non-enzymatic glycation. Based on the specific activity of D-(U- $\left.{ }^{14} \mathrm{C}\right)$-glucose $\left(1 \times 10^{3} \mathrm{cpm} / \mathrm{nmol}\right)$, the incorporation of $4 \times 10^{3} \mathrm{cpm}$ in $8 \mathrm{nmol} \mathrm{HCII}$ represents an average of $0.5 \mathrm{~mol}$ glucose $/ \mathrm{mol}$ protein. The presence of HSA did not promote HCII glucose incorporation, while, as previously reported [13], HSA incorporated also $0.5 \mathrm{~mol}$ glucose $/ \mathrm{mol}$ albumin (Fig. 1 c).

These results suggest that HCII can be glycated at normal physiological glucose concentrations but is more likely at a concentration that is close to that expected in severely diabetic patients.

Since plasma time of elimination of HCII in man is 2.5 days [17], the HCII solution that lost $20 \%$ (corrected for control loss) after 2.5 days of incubation was used in the kinetics experiments, to determine its effectiveness in neutralizing the activity of thrombin. No attempt was made to isolate the pure glycated HCII because the goal was to investigate how the overall kinetic property of HCII may be affected in the blood of diabetic patients where the circulating HCII is assumed to be a mixture of
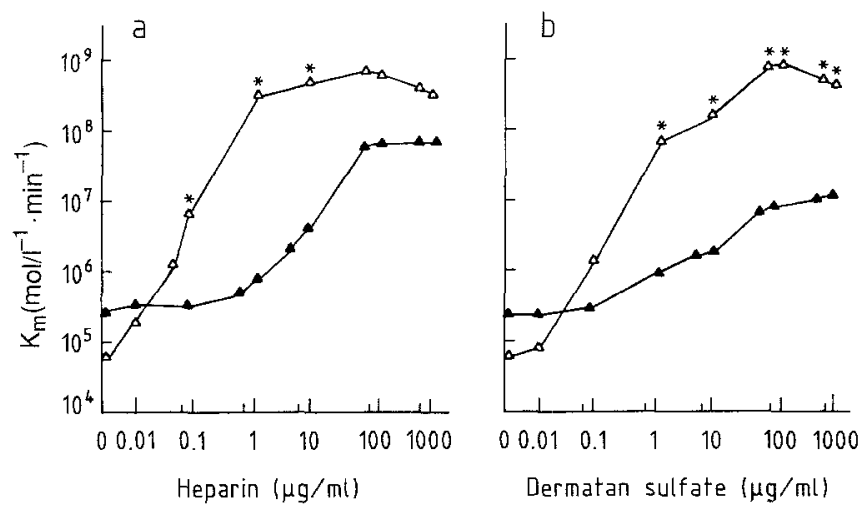

Fig. 2a and b. Kinetics of thrombin inhibition by HCII in the presence of heparin and dermatan-sulfate. Second-order rate constants $\left(\mathrm{K}_{\mathrm{m}}\right)$ of inhibition (control HCII $\triangle$-glycated HCII $\Delta$ ) were plotted as a function of heparin and dermatan-sulfate concentrations. ${ }^{*} p<0.01$ 
glycated and non-glycated HCII. The inactivation of thrombin by $\mathrm{HCII}$ in the presence of heparin or dermatansulfate was monitored by measuring the residual thrombin activity through the hydrolysis of chromogenic substrate S-2238 in $0.15 \mathrm{~mol} \mathrm{NaCl}, 0.02 \mathrm{~mol} / \mathrm{l}$ Tris- $\mathrm{HCl}$, $\mathrm{pH}$ 7.4.

Effects of glycation of HCII on the heparin and dermatan sulfate-dependent inhibition of thrombin by HCII are shown in Figures $2 a$ and $2 b$. The glycation of HCII resulted in a remarkable decrease of the maximum $\mathrm{K}_{\mathrm{m}}$ of the reaction between $\mathrm{HCII}$ and thrombin. Unexpectedly, no decrease in $\mathrm{K}_{\mathrm{m}}$ inhibition of glycated HCII was observed in the presence of excess amounts of heparin, while $K_{m}$ of inhibition of HCII decreased at a heparin concentration above $50 \mu \mathrm{g} / \mathrm{ml}$.

\section{Discussion}

These in vitro studies indicate that HCII can be glycated at a normal physiological concentration of glucose but even more so at a concentration expected to be encountered in severely diabetic patients. This property is clearly demonstrated by the radioactivity incorporation studies. The maximum loss of HCII activity and the maximum incorporation of radioactivity were observed between 7 and 10 days. These in vitro studies were kept as close to physiological conditions as possible, but obviously, glycation of proteins other than HCII occurs in vivo. However, although more blood proteins are glycated in circulating blood than just HCII, the HCII is, nevertheless, exposed to a steady-state concentration of glucose that is simulated in these studies. Thus, in vivo, glycation would not be expected to be less efficient than the in vitro glycation demonstrated. This affirmation, however, is supported by the experiments carried out in the presence of albumin at physiological concentration. The decrease of HCII activity and the HCII glucose incorporation were not significantly promoted by the presence of albumin.

Albumin and HCII incorporated the same amount of glucose/mol protein. Interestingly, a similar amount is incorporated by glycated antithrombin III [18]. These data support the hypothesis that the steady-state concentration of glucose may promote an equivalent glucose-protein linkage formation between various proteins.

Under the in vitro conditions in this investigation, the second order rate constant for the inhibition of thrombin by glycated HCII was found to be three times smaller than that of normal HCII. This result means that glycated HCII is three times weaker than normal HCII as an inhibitor of thrombin.

The relevance of our study is that HCII can be glycated at glucose concentrations found in the blood. However, the possible link, in vivo, between the glycation of HCII, antithrombin III or other clotting factors, and the coagulation alterations seen in diabetes, remains to be elucidated.

\section{References}

1. Briginshaw GF, Shanberge JN (1974) Identification of two distinct heparin cofactor in human plasma. Separation and partial purification. Arch Biochem Biophys 161: 683-690

2. Tollefsen DM, Blank MK (1981) Detection of a new heparin-dependent inhibitor of thrombin in human plasma. J Clin Invest 68 : 589-596

3. Tollefsen DM, Majerns DM, Blank MK (1982) Heparin cofactor II. Purification and properties of a heparin-dependent inhibitor of thrombin in human plasma. J Biol Chem 257: 2162-2169

4. Wunderwald P, Schrenk WJ, Port H (1982) Antithrombin BM from human plasma: an antithrombin binding moderately to heparin. Thromb Res 25: 177-192

5. Griffith MJ, Noyes CM, Church FC (1985) Reactive site peptide structural similarity between heparin cofactor II and antithrombin III. J Biol Chem 260: 2218-2225

6. Tollefsen DM (1984) Activation of heparin cofactor II by heparin and dermatan sulfate. Nouv Rev Fr Hematol 26: 233-237

7. Jones RL, Peterson CM (1979) Reduced fibrinogen survival in diabetes mellitus. J Clin Invest 63: 485-493

8. Jones RL (1985) Fibrinopeptide A in diabetes mellitus: relation to the levels of blood glucose, fibrinogen disappearance, and hemodynamic changes. Diabetes 34: 836-841

9. Ceriello A, Curcio F, Dello Russo P, Giugliano D (1984) Nonenzymatic glycosylation reduces antithrombin III activity. Thromb Haemostas 52: 363 (letter)

10. Brownlee M, Vlassara H, Cerami A (1984) Inhibition of heparincatalyzed human antithrombin III activity by nonenzymatic glycosylation. Diabetes 33:532-535

11. Ceriello A, Giugliano D, Quatraro A, Consoli G, Stante A, Dello Russo P, D'Onofrio F (1987) Induced-hyperglycemia alters antithrombin III activity but not its plasma concentration in healthy normal subjects. Diabetes 36: 320-323

12. Trueb B, Holenstein CG, Fisher RW, Winterhalts KH (1980) Nonenzymatic glycosylation of proteins. A warning. J Biol Chem 255:6717-6720

13. Day JF, Thorpe SR, Baynes JW (1979) Nonenzymatically glucosylated albumin: in vitro preparation and isolation from normal human serum. J Biol Chem 254: 595-597

14. Parker KA, Tollefsen DM (1985) The protease specificity of heparin cofactor II. Inhibition of thrombin generated during coagulation. J Biol Chem 260: 3501-3505

15. Griffith MJ (1982) Measurement of the heparin enhanced-antithrombin III/thrombin reaction rate in the presence of synthetic substrate. Thromb Res 25:245-253

16. Eble AS, Thorpe SR, Baynes JW (1983) Nonenzymatic glucosylation and glucose-dependent linking of protein. J Biol Chern 258: 9406-9412

17. Sié P, Dupoy D, Pichon J, Bonen B (1985) Turnover study of heparin co-factor II in healthy man. Thromb Haemostas 54: 635638

18. Villanueva GB, Allen N (1988) Demonstration of altered antithrombin III activity due to nonenzymatic glycosylation at glucose concentration expected to be encountered in severely diabetic patients. Diabetes 37: 1103-1107

Received: 10 April 1989

and in revised form: 27 October 1989

Dr. A. Ceriello

Viale Lincoln 4

Parco Mecos

I-81100 Caserta

Italy 